\title{
Chronic kidney disease in children in Turkey
}

\author{
Kenan Bek • Sema Akman • Ilmay Bilge • \\ Rezan Topaloğlu • Salim Çalıșkan • Harun Peru • \\ Nurcan Cengiz • Oğuz Söylemezoğlu
}

Published online: 18 December 2008

(C) IPNA 2008

\section{Erratum to: Pediatr Nephrol}

DOI 10.1007/s00467-008-0998-4

There is an error in the Acknowledgment of this article. Harika Alpay and Nese Biyikli are the participating physicians from the Marmara University.

The authors apologize for this error.

The original version of the article can be found under http://dx.doi. org/10.1007/s00467-008-0998-4.

K. Bek $(\square)$

Pediatric Nephrology, Ondokuz Mayis University,

Kurupelit, Samsun 55100, Turkey

e-mail: kenanbek2000@yahoo.com

\section{S. Akman}

Pediatric Nephrology, Faculty of Medicine, Akeniz University,

Antalya, Turkey

I. Bilge

Pediatric Nephrology, Capa Medical Faculty, Istanbul University, Istanbul, Turkey

R. Topaloğlu

Pediatric Nephrology and Rheumatology,

Hacettepe University Faculty of Medicine,

Ankara, Turkey
S. Çalışkan

Pediatric Nephrology, Cerrahpaba Medical Faculty,

Istanbul University,

Istanbul, Turkey

H. Peru

Pediatric Nephrology, Meram Medical Faculty,

Selçuk University,

Anatolia, Turkey

N. Cengiz

Pediatric Nephrology, Faculty of Medicine,

Başkent University,

Adana, Turkey

O. Söylemezoğlu

Pediatric Nephrology, Faculty of Medicine, Gazi University,

Ankara, Turkey 